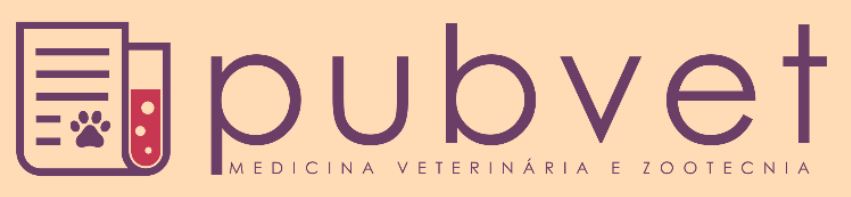

https://doi.org/10.31533/pubvet.v15n07a859.1-8

\title{
Aplicação da ozonioterapia na clínica de pequenos animais: vias de administração, indicações e efeitos adversos: Revisão
}

\author{
Bianca de Brito $^{1 *}$, Erica Cristina Rocha Roier ${ }^{2} \odot$ (D), Francesca de Oliveira $\operatorname{Lemos}^{2}{ }^{\circ}$, Mario dos \\ Santos Filho ${ }^{20}$ (D)
}

${ }^{I}$ Discente de Graduação do Curso de Medicina Veterinária, Universidade de Vassouras. Vassouras, RJ, Brasil.

${ }^{2}$ Docente do Curso de Graduação de Medicina Veterinária, Universidade de Vassouras. Vassouras, RJ, Brasil.

*Autor para correspondência, E-mail: bibitroferreira@gmail.com

\begin{abstract}
Resumo. As terapias integrativas, como a ozonioterapia, laserterapia e acupuntura, podem ser introduzidas como adjuvantes na recuperação de diferentes afecções do paciente, e vêm crescendo sua aplicabilidade na medicina veterinária. A ozonioterapia é uma técnica complementar que consiste na utilização do gás ozônio medicinal. Este se constitui um gás instável, incolor, com odor característico e se forma por meio de descargas elétricas sobre uma molécula de oxigênio medicinal. Como artifício terapêutico, potencializa a ação cicatrizante, acelerando a resolução das lesões. Além disso, possui propriedades viricida, fungicida e bacteriana, atua como agente antiálgico, antisséptico e anti-inflamatório. $\mathrm{O}$ objetivo do presente trabalho é realizar uma revisão de literatura a respeito da ozonioterapia, levando em conta suas principais indicações, via de administração, efeitos adversos e positivos, bem como o auxílio do tratamento associado a condutas terapêuticas dentro da medicina veterinária.
\end{abstract}

Palavras-chave: Gás ozônio, ozonioterapia, pequenos animais, tratamento adjuvante

\section{Application of ozonetherapy in the small animal practice clinics: administration uses, indications and adverse effect: Review}

\begin{abstract}
Complementary therapies, such as ozonotherapy, laser therapy and acupuncture, can be introduced as adjuvants in the recovery of different conditions of the patient, and their applicability in veterinary medicine has been growing. Ozonotherapy is a complementary technique that consists in the use of medical ozone gas. This is an unstable, colorless gas with a characteristic odor and is formed by means of electrical discharges over a medicinal oxygen molecule. As a therapeutic device, it enhances the healing action, accelerating the cicatrization of lesions. In addition, it has viricidal, fungicidal and bacterial properties, acts as an antialgic, antiseptic and anti-inflammatory agent. The main goal of this article is to carry out a literature review about ozonotherapy, taking into account its main indications, administration uses, adverse and positive effects, as well as the treatment aid associated with therapeutic approaches within veterinary medicine.
\end{abstract}

Keywords: Adjuvant treatment, ozone gas, ozone therapy, small animals

\section{Aplicación de la ozonoterapia en la clínica de pequeños animales: vías de administración, indicaciones y efectos adversos: Revisión}

Resumen. Las terapias complementarias, como la ozonoterapia, la terapia con láser y la acupuntura, pueden introducirse a modo de adyuvantes en la recuperación de diferentes afecciones del paciente, y su aplicabilidad en medicina veterinaria ha ido en aumento. La 
ozonoterapia es una técnica complementaria que consiste en utilizar gas ozono medicinal. Se trata de un gas inestable, incoloro y de olor característico que se forma mediante descargas eléctricas sobre una molécula de oxígeno medicinal. A modo de dispositivo terapéutico, potencia la acción cicatrizante, acelerando la resolución de las lesiones. Además, tiene propiedades viricidas, fungicidas y bacterianas, actúa como agente antiálgico, antiséptico y antiinflamatorio. El objetivo del presente trabajo es realizar una revisión de la literatura sobre ozonoterapia, teniendo en cuenta sus principales indicaciones, vía de administración, efectos adversos y positivos, también ayuda con tratamientos terapéuticos dentro de la medicina veterinaria.

Palabras clave: Animales pequeños, gas ozono, ozonoterapia, tratamiento adyuvante

\section{Introdução}

Com a constante evolução da domesticação animal, a sociedade contemporânea tornou-se adepta dos maiores cuidados e exigências para estes. É possível observar a importância do animal de estimação como um membro da família, havendo uma construção de relação afetiva. Dessa forma, a medicina veterinária vem sendo mais explorada e aperfeiçoada, aumentando a exigência por especialistas, meios de diagnósticos e tratamentos alternativos para promover a expectativa de vida e o bem-estar dos animais. A busca por tratamentos integrativos vem se destacando na área de clínica médica de pequenos animais, uma vez que as propriedades que auxiliam na conduta terapêutica, podem agir como adjuvante e, por conta de seu preço acessível e pouco invasivo, pode ser uma alternativa viável ao tutor. Porém, deve-se trabalhar a aceitação e importância da técnica aos tutores e o preço da capacitação dos profissionais não é barato.

Uma importante terapia adjuvante vem a ser o uso do gás ozônio $\left(\mathrm{O}_{3}\right)$ que, quando utilizado de forma medicinal, desempenha um papel promissor por ser de fácil aplicação e de baixo custo comparado a outros tipos de terapias e fármacos (Penido et al., 2010; Schwartz \& Sánchez, 2012).

O objetivo do presente trabalho é realizar uma revisão de literatura a respeito da ozonioterapia, levando em conta suas principais indicações, via de administração e efeitos benéficos e prejudiciais desse tratamento associado às condutas terapêuticas dentro da medicina veterinária.

\section{Ozonioterapia}

O ozônio é uma molécula com poder altamente oxidativo, formada a partir de três átomos de oxigênio. No ambiente natural sua formação ocorre por meio de altas descargas elétricas promovidas por fatores ambientais como os raios. Pelas altas descargas elétricas, ocorre a quebra da molécula de oxigênio, um dos seus átomos se dispersa realizando assim uma nova ligação a uma molécula de oxigênio dando origem a molécula de ozônio (Penido et al., 2010; Schwartz \& Sánchez, 2012). A junção proveniente de oxigênio hospitalar e ozônio, basicamente nas proporções de $95 \%$ a 99,5\% e 5\% a 0,05\%, respectivamente, é a fase ativa e estável de ozônio, para aplicação.

Embora ainda careça de estudos mais elucidativos, o gás ozônio vem sendo utilizado desde a primeira Guerra Mundial, quando era instituído no tratamento de feridas infectadas, queimaduras e fístulas dos soldados feridos (Batinjan et al., 2014). Também ao longo da primeira guerra mundial, o ozônio misturado com oxigênio foi usado para desinfetar um ferimento na pata de um equino (Freitas, 2011).

A ozonioterapia nos dias atuais é uma terapia médica complementar aplicada juntamente com a medicina alopática já existente e preconizada para cada tipo de afecção. O gás ozônio, quando utilizado de forma medicinal, desempenha um papel promissor por ser de fácil aplicação e de baixo custo comparado a outros tipos de terapias e fármacos (Penido et al., 2010). No caso de se optar por seu uso, a aplicabilidade do $\left(\mathrm{O}_{3}\right)$ formado por aparelhos ozonizadores (Figura 1) deve ser em curto espaço de tempo, pois o gás apresenta características altamente reativas e instáveis, retornando rapidamente a forma de $\mathrm{O}_{2}$ (Aboz, 2017), tendo sua meia vida em torno de 40 minutos (Penido et al., 2010).

Considerando como fatores recomendados a instituição desta modalidade terapêutica, pode-se destacar a redução à resistência de antibióticos para os casos de período extenso de tratamento, bem 
como os possíveis efeitos colaterais e o custo dos fármacos utilizados (Wollheim et al., 2020). Sua aplicação no uso para cicatrização por segunda intenção possui interessante valia, uma vez que acelera e otimiza o processo de granulação da região, reduz a inflamação por meio de suas propriedades moduladoras de citocinas, e melhora a perfusão sanguínea local (Penido et al., 2010).

Outros métodos de utilização envolvem o uso por meio da infusão em solução fisiológica ou transfusão sanguínea, otimizando o poder oxidativo no tecido periférico, com redução dos radicais livres nos tecidos cardíaco, renal e hematopoiético, favorecendo a circulação e renovação das células componentes dos respectivos tecidos.

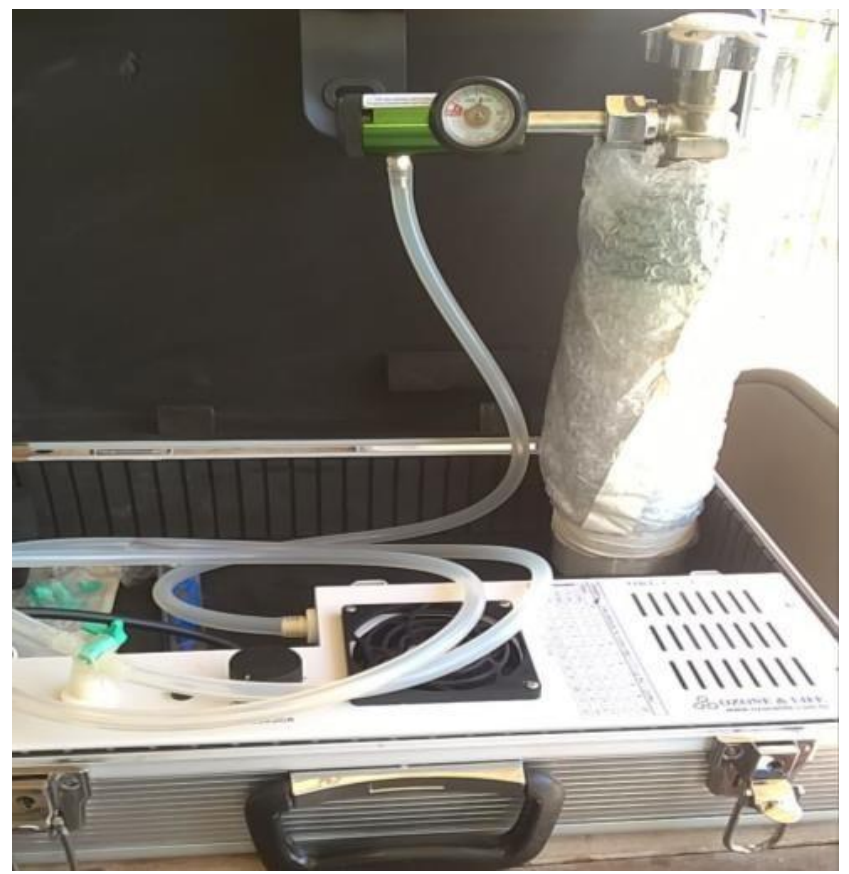

Figura 1. Aparelho gerador de ozônio, evidenciando manômetros responsáveis pela verificação da conversão. Fonte: Imagem cedida pelo Médico Veterinário Rodrigo Stival Fonseca, 2020.

\section{Cuidados no manuseio e efeitos colaterais}

Para evitar riscos ao paciente e ao profissional de atuação, torna-se de extrema importância as técnicas precisas de preparo e concentrações adequadas, pois contraindicações e efeitos colaterais não devem ser subestimados (Belegote et al., 2018).

O uso da técnica adequada pode levar a poucos efeitos colaterais. No entanto, quando o ozônio é utilizado em concentrações altas e com a exposição do gás por tempo prolongado sendo maior que 30 minutos, poderá provocar efeitos diversos como: irritação de mucosa e olhos, distúrbios na visão, perda de memória, febre, fadiga, fibrose, bronquite, além de variações no trato respiratório como a dispneia (Freitas, 2011).

O ozônio, quando inalado de forma direta, pode apresentar efeito tóxico no trato respiratório superior, podendo ocasionar irritação das vias superiores, dores de cabeça, rinite e eventualmente vômito e náusea, embora esses efeitos não sejam frequentemente reportados. Dessa forma, torna-se inapropriado a aplicação do gás $\mathrm{O}_{3}$ por via intravenosa direta e por via inalatória, visto que ao entrar em contato com o epitélio mucociliar causa efeitos irritativos, e quando em contato com os alvéolos, tanto por via direta inalatória, quanto por via hematogênica, se mostra tóxico, causando colapso pulmonar (Marques \& Campebell, 2017).

O efeito oxidativo e a alta reatividade do gás ozônio podem ocasionar a lesão do epitélio. Caso a terapia seja administrada de forma repetitiva e excessiva, é possível que ocorra o aumento da descamação do epitélio glandular e essas células são liberadas com o aspecto de grumos retardando o processo de cicatrização (Penido et al., 2010). 


\section{Contraindicações}

A administração do gás ozônio não é indicado em hipótese alguma pela via inalatória, por ser uma via altamente tóxica para humanos e animais, pois as condições bioquímicas e anatômicas do pulmão, faz com que ele não suporte o estresse oxidativo que o ozônio é capaz de promover. Não é indicado em pacientes portadores de doenças endócrinas como hipertireoidismo, uma vez que ozônio tem propriedades em estimular a produção de hormônios da tireoide. A ozonoterapia não deve aplicada nos pacientes com diabetes e nos deficientes da enzima glicose-6-fosfato-dihidrogenase, pois a ação rápida do processo oxidativo favorece a ocorrência de quadros de distúrbios de coagulação. Por esse mesmo motivo, não se deve utilizar nos casos de anemia severa e hemorragia ativa (Penido et al., 2010).

\section{Indicação}

Utilizado como prática terapêutica, o gás ozônio possui propriedades viricida, fungicida e bactericida, e seu mecanismo de ação resulta da oxidação da membrana celular e componente citoplasmáticos causando a morte dos microrganismos envolvidos com o processo em questão (Wollheim et al., 2020). $\mathrm{O}_{3}$ pode proporcionar uma alta capacidade de penetração nos tecidos melhorando a oxigenação e circulação agindo como agente antiálgico, antisséptico, anti-inflamatório, pois atuam sobre mediadores da inflamação, inibindo a síntese de prostaglandina e na destruição de citocinas, promovendo bloqueio da inflamação (Srinivasan \& Chitra, 2015; Tiwari et al., 2017). Outras atribuições trazidas pelo ozônio é o estímulo do sistema imune, síntese de anticorpos, ativação de linfócitos T, aumento da oxigenação e do metabolismo celular por meio da vasodilatação e também redução da agregação plaquetária (Penido et al., 2010). Pode ser aplicado em auxílio ao processo de cicatrização aumentando a migração de fibroblastos para a lesão e por meio da estimulação da circulação sanguínea na área (Chagas et al., 2019; Xiao et al., 2017).

\section{Vias de administração e aplicações terapêuticas}

Segundo Penido et al. (2010), o mecanismo de ação do ozônio varia de acordo com o motivo da utilização e forma de aplicado. Em lesões cutâneas, a terapia é empregada para melhorar a circulação sanguínea do paciente fazendo com que aumente também a oxigenação celular. A auto-hemoterapia quando utilizada, tem por objetivo atuar como ação bactericida e anti-inflamatória. No tratamento via retal, o ozônio é dissolvido diretamente na mucosa intestinal, com resposta antioxidante, ação imune estimulante e estabilização da flora intestinal (Chagas et al., 2019). O gás será absorvido pelas células da parede intestinal e é difundido por meio dos tecidos através do aumento da pressão retal, facilitando seu transporte até o sítio de ação (Marques \& Campebell, 2017).

As formas de aplicação da terapia são bastante flexíveis, variando de acordo com a enfermidade, podendo ser administrado de forma subcutânea, intramuscular, intravenosa, retal, intra-vaginal e autohemoterapia ozonizada (Lima \& Silva, 2019). Essa flexibilidade garante que a ação do gás possa ter efeito esperado em nível local, regional ou sistêmico. Quando o efeito desejado for de ação local ou regional, a administração ideal deverá ser por via tópica, subcutânea, muscular, intra ou peri-articular. Se o efeito desejado for de ação sistêmica, a via de eleição é a venosa e retal (Marques \& Campebell, 2017). A aplicação do $\mathrm{O}_{3}$ de forma local atua como anti-inflamatório, auxiliando na dor e redução do edema, por meio da neutralização dos mediadores neuroquímicos e pro-inflamatórios (quinina, histamina e bradicina), facilitando a metabolização e excreção, além de inibir a cicloxigenase II (Ferreira et al., 2013). O método terapêutico de forma tópica pode ser administrado por meio de solução de água ozonizada ou óleo ozonizado, sendo aplicado diretamente no local de eleição ou por meio de bolsa "bag", tendo esta última melhor cobertura no revestimento da região lesionada. O material que constitui o "bag" deve ser ozônio-resistente para que a concentração de gás seja restrita no interior deste por um tempo ideal, sem que tenha porosidade que possam favorecer a volatização. Seu uso se dá, principalmente, para aplicação em lesões, sejam elas pós-operatórias, escaras e feridas abertas (Silva et al., 2018) e que com a bag, a aplicação do ozônio se prolongue por período de 20 a 30 minutos diretamente no local da lesão (Hayashi \& Friolani, 2018).

O tratamento local vem tendo resultados promissores, pois os efeitos benéficos são notados desde a primeira aplicação, uma vez que colaboram com a desinfecção e limpeza da lesão, desde um tecido mais 
contaminado e necrosado ou naqueles em que há um retardo de cicatrização, sendo o efeito dosedependente (Marques \& Campebell, 2017).

\section{Veículos para o uso do ozônio}

O óleo ozonizado pode ser um importante meio para uso do ozônio. É formado por meio do borbulhamento contínuo da mistura do gás, e suas frações proporcionais adequadas, com óleo vegetal, em temperatura ambiente até o momento que se solidifique. Seu uso é indicado em aplicações tópicas para o tratamento de infecções locais, feridas traumáticas e queimaduras. Quando o óleo ozonizado entra em contato com o tecido ocorre a liberação do ozônio, favorecendo o processo cicatricial. Pode ser armazenado ao abrigo da luz e sob refrigeração com duração de validade até um ano (Marchesini \& Ribeiro, 2020).

A auto-hemoterapia é outra técnica descrita, na qual uma quantidade de sangue é retirada do animal e misturada com ozônio, com posterior reaplicação. Essa via tem por objetivo a atuação de forma sistêmica, com intenção de estimular respostas imunes, ativar a ação antioxidante e circulatória (Moura, 2018). Em uma das suas variações, a auto-hemoterapia maior, o sangue coletado e ozonizado é colocado em uma bolsa de transfusão com anticoagulante, com posterior homogeneização de, ao menos 5 minutos. Após o processo, o sangue é reinoculado por via endovenosa. Da mesma forma acontece com a auto-hemoterapia menor, em que uma porção de sangue é tratada externamente, porém é reinfundido pela via intramuscular ou subcutânea (Borges et al., 2019).

A aplicação por meio do uso de solução fisiológica também pode ser uma opção. Neste veículo, a solução deverá ser previamente enriquecida com ozônio e a infusão venosa ocorrer de forma lenta. Contudo existe controvérsia sobre a velocidade de infusão, uma vez que o ozônio pode se tornar indisponível com o passar do tempo, e nesses casos se necessita de infusão lenta, devido aos processos relacionados aos efeitos colaterais diretos no leito vascular, como vasculites (Hayashi \& Friolani, 2018; Marques \& Campebell, 2017).

\section{Aplicações terapêuticas descritas em casos clínicos}

A utilização do gás ozônio de forma tópica mostrou-se eficaz com o uso de óleo e água ozonizados no tratamento de lesões fúngicas em tartarugas (Marchesini \& Ribeiro, 2020). Silva Júnior (2018) descreve a cicatrização mais rápida de feridas contaminadas em um cão com a prática de ozonioterapia.

Levando em conta o ozônio como terapia complementar nos tratamentos oncológicos foi observado por Sousa (2009) que, ao se incluir em seu protocolo o uso adjuvante de ozonioterapia por meio de solução fisiológica em infusão, juntamente aos quimioterápicos, o tratamento de tumor venéreo transmissível (TVT) teve significativa diminuição da quantidade de sessões quimioterápicas com sulfato de vincristina.

Usando-o com o objetivo de propriedade anti-inflamatória, Teixeira et al. (2013) descreveram que a insuflação retal utilizando o gás ozônio e a aplicação de ozônio injetado em pontos de acupuntura, evidenciou ser tão eficaz quanto a utilização de meloxicam para analgesia em recuperação cirúrgica em caninos submetidos a ovário-histerectomia $(\mathrm{OVH})$ eletiva.

Gonçalves et al. (2020a) relatam o uso da ozonioterapia como terapia adjuvante no tratamento de erliquiose canina, onde observou-se resposta significativa ao aumento de plaquetas, embora não respondendo a terapia padrão para doença.

Um estudo envolvendo Leishmaniose Visceral Canina reportou melhora clínica do paciente, com atenuação dos sinais clínicos, como dor e febre, e alterações hematológicas e tegumentares, após instituição do acréscimo da terapia por ozônio, sendo complementar no tratamento empregado. Essa melhora ocorreu após quarta aplicação do ozônio (Gonçalves et al., 2020b).

Fritzen et al. (2018) descrevem o uso da ozonioterapia auxiliando ao tratamento de otite externa canina (Figura 2), sendo este realizado por meio de infusão de gás diretamente no ouvido do paciente 
(Figura 3) e, aliado a isto, com aplicação de óleo ozonizado levando a melhora do quadro (Figura 4). Nesse caso específico, foi usado óleo de girassol.

Da mesma forma, há relatos do progresso de cicatrização de lesões por mordedura de cão em um paciente felino. Nesse caso, foram preconizadas 7 aplicações de ozonioterapia, pela técnica subcutânea e óleo de girassol ozonizado aplicado diretamente sobre o ferimento. Como resultado, obteve-se cicatrização da ferida em 25 dias (Dagostin, 2019).

Ainda com relação a infecções cutâneas, Borges et al. (2019) relatam a utilização da ozonioterapia complementando o tratamento de dermatite bacteriana em dois cães da raça Golden Retriever realizada a técnica de "bag", onde observou melhor resposta frente aos antibióticos, atentando ao fato da doença nesses animais estarem em curso crônico, e desta forma optaram por associar a terapia.

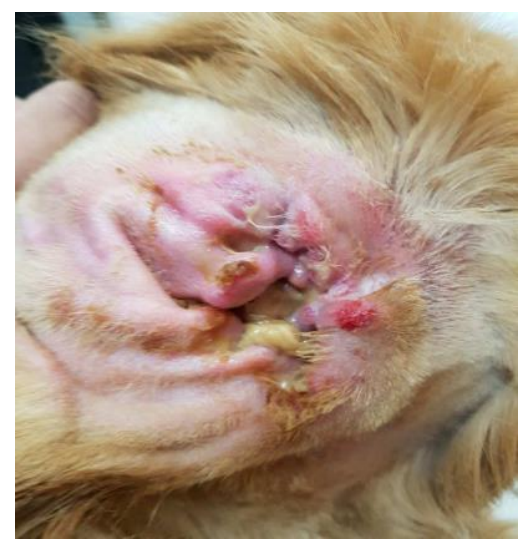

Figura 2. Conduto auditivo de um cão com secreção e lesões hiperêmicas, antes do tratamento com ozônio. Fonte: Fritzen et al. (2018).

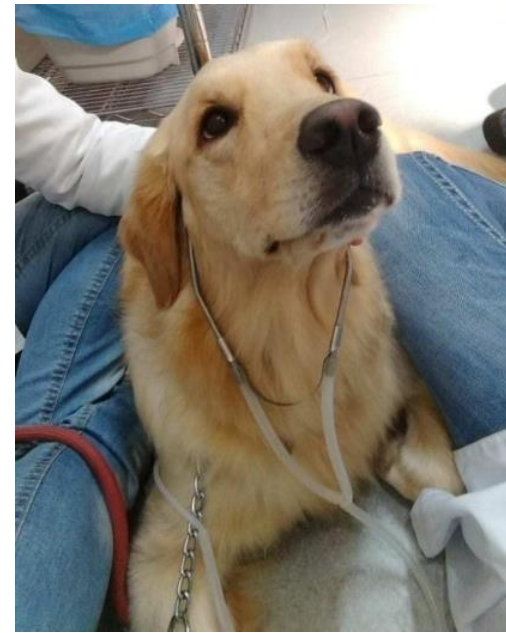

Figura 3. Tratamento de otite bacteriana com infusão de gás ozônio. Fonte: Fritzen et al. (2018).

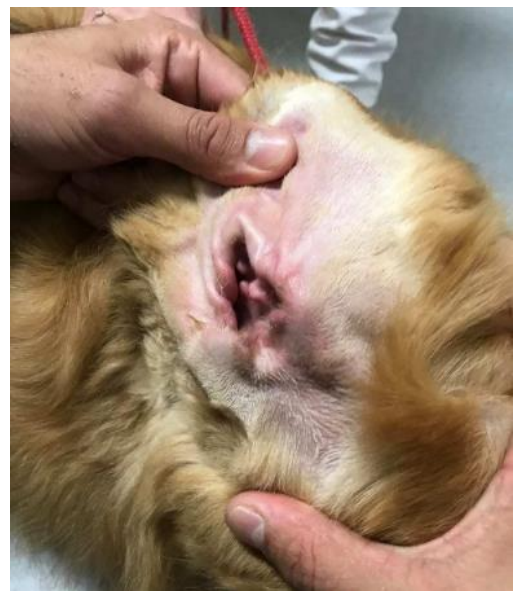

Figura 4. Ouvido do cão após o tratamento. Fonte: Fritzen et al. $(\underline{2018})$

As doenças crônicas também possuem indicação de aplicação, como a associação de ozonioterapia, associado a acupuntura, no tratamento de animais que apresentam Doença renal crônica. Foi observado melhora significativa do quadro clínico de pacientes onde realizaram esta associação (Ferreira, 2019). Algumas descrições de uso em doenças infecciosas caninas, como parvovirose e cinomose, merecem destaque. Traldi (2019) descreveu o uso da ozonioterapia de forma complementar no tratamento, por via retal na parvovirose canina e por meio de pontos de acupuntura no subcutâneo de cães com cinomose. A resposta foi o poder de resolução de metade do tempo de internação média nos pacientes com parvovirose e redução das miocloniais e sinais neurológicos nos pacientes com cinomose.

\section{Regulamentação no Brasil e no mundo}

O emprego do ozônio de forma terapêutica no Brasil ainda é muito reduzido. Contudo, vem sendo estudado amplamente na medicina humana e veterinária, pois há pouco conhecimento da sua aplicação terapêutica e conclusivo suporte científico, justamente por possuir muita polêmica quanto ao seu uso.

Entretanto, o estudo sobre a técnica vem avançando e se destacando cada vez mais no mundo dentro de muitas possibilidades de áreas de atuação, por conta de resultados positivos no tratamento de diversas doenças que foram reportados pelos pesquisadores e clínicos. O acesso ao recurso e a técnica são simples e acabam por facilitar a aplicação em fins terapêuticos.

Recentemente, o uso da ozonioterapia passou a ser regulamentada e reconhecida pelo Conselho Federal de Medicina Veterinária (CFMV), atuando como aplicação prática na clínica médica no tratamento de animais por médicos-veterinários. 
Para a realização da técnica é preciso que o profissional esteja respaldado conforme a literatura pelas vias indicadas e dose, promovendo segurança e eficiência para o tratamento de uma afecção, sendo de forma isolada ou complementar. Embora a autorização seja recente, existe a necessidade da criação de Associações que embasem protocolos e compilem os dados obtidos pelos usuários.

\section{Considerações finais}

Levando em consideração os materiais revisados, sabemos que o gás ozônio vem sendo cada vez mais estudado, reconhecido e aplicado como modalidade terapêutica complementar em diferentes enfermidades nas medicinas humana e veterinária. Vale ressaltar que seu uso com propriedades bactericida, viricida e fungicida, bem como ação imunomoduladora necessitam de mais informações que possam conflitar sua ação com a resposta esperada para um tratamento.

De forma geral, compilando-se na literatura os relatos e trabalhos, o ozônio medicinal vem mostrando eficiência em casos distintos, crescendo enormemente o seu uso, por conta de maior acessibilidade aos equipamentos por parte dos médicos-veterinários, encorajando o uso da técnica no cotidiano. Contudo, mais estudos são necessários a fim de determinar posologia e doses adequadas, para demonstrar sua aplicação como alternativa monoterápica específica.

\section{Referências}

Aboz, Ozonioterapia. (2020). Disponível em: https://www.aboz.org.br/. Acesso em: 06 maio 2020

Batinjan, G., Zore, I. F., Vuletić, M., \& Rupić, I. (2014). The use of ozone in the prevention of osteoradionecrosis of the jaw. Saudi Medical Journal, 35(10), 1260-1263.

Belegote, I. S., Penedo, G. dos S., Silva, Í. C. B., Barbosa, A. A., Belo, M. T. N., \& Neto, O. I. (2018). Tratamento de doença periodontal com ozônio. Brazilian Journal of Surgery and Clinical Research, 23(2), 101-104.

Borges, T. L., Marangoni, Y. G., Joaquim, J. G. F., Rossetto, V. J. V., \& Nitta, T. Y. (2019). Ozonioterapia no tratamento de cães com dermatite bacteriana: relato de dois casos. Revista Cientifica de Medicina Veterinária. ISSN 1679-7353, Ano XVI, No 32 - Janeiro de 2019. Caso., 32, $1-11$.

Chagas, N. T. C., Rocha, C. L. R., Silva, R. B. T., Santos, K. M. M., \& Hirano, L. Q. L. (2019). Tratamento de ferida em Coendou prehensilis (Rodentia: Erethizontidae) com laserterapia e ozonioterapia: relato de caso. Arquivo Brasileiro de Medicina Veterinária e Zootecnia, 71(3), 953958. https://doi.org/10.1590/1678-4162-10872 .

Dagostin, R. (2019). Uso de ozonioterapia no tratamento de ferida por modedura em um felino-relato de caso. Curitibanos, SC.

Ferreira, A. V. F. (2019). Insuficiência renal crônica em cães: uma abordagem em medicina veterinária integrativa e complementar-relato de caso. Universidade Federal de Uberlândia.

Ferreira, S., Mariano, R. C., Garcia Júnior, I. R., \& Pellizzer, E. P. (2013). Ozonioterapia no controle da infecção em cirurgia oral. Revista Odontológica de Araçatuba, 34(1), 36-38.

Freitas, A. I. A. (2011). Eficiência da Ozonioterapia como protocolo de tratamento alternativo das diversas enfermidades na Medicina Veterinária. PUBVET, 5(30), Art-1192. https://doi.org/: 10.22256/pubvet.v5n30.1194.

Fritzen, M., Tortelly Neto, R., \& Vonsowski, J. R. T. (2018). Aplicação da ozonioterapia em cão com otitem- Relato de caso. Arquivos Brasileiros de Medicina Veterinária, 1(2), 147-159.

Gonçalves, B. P., Castro, L. M., Pinto, H. G. F., \& Santos Filho, M. (2020a). Terapia adjuvante com uso de solução fisiológica ozonizada em cão com trombocitopenia persistente-relato de caso. Research, Society and Development, 9(9), e167997234-e167997234. https://doi.org/10.33448/rsd-v9i9.7234.

Gonçalves, J. O. S., Paiva, P. O., \& Oliveira, L. B. G. (2020b). Uso da ozonioterapia como auxiliar no tratamento de cão portador de leishmaniose: relato de caso. PUBVET, 14(1), 1-4. https://doi.org/10.31533/pubvet.v14n1a495.1-4.

Hayashi, M. P., \& Friolani, M. (2018). Aplicabilidade clínica cirúrgica da ozonioterapia em pequenos animais: Revisão de literatura. Revista Unimar Ciências, 27(1-2). 
Lima, H. A. C., \& Silva, P. T. G. (2019). Aplicabilidade da ozonioterapia no tratamento de ferida secundária a fratura exposta- Relato de caso. Anais Do $18^{\circ}$ Simpósio de TCC e $15^{\circ}$ Seminário de IC Do Centro Universitário ICESP, 1663-1668.

Marchesini, B. F., \& Ribeiro, S. B. (2020). Efeito da ozonioterapia na cicatrização de feridas. Fisioterapia Brasil, 21(3), 281-288. https://doi.org/10.33233/fb.v21i3.2931.

Marques, A. S., \& Campebell, R. C. (2017). Ozonioterapia em feridas de equinos-revisão. Revista Científica de Medicina Veterinária Do UNICEPLAC, 4(2), 31-45.

Moura, L. (2018). Auto-hemoterapia.

Penido, B. R., Lima, C. A., \& Ferreira, L. F. L. (2010). Aplicações da ozonioterapia na clínica veterinária. PUBVET, 4, Art-974.

Schwartz, A., \& Sánchez, G. M. (2012). Ozone therapy and its scientific foundations. Ozone Therapy Global Journal, 2(1), 199-232.

Silva Júnior, J. I. S. (2018). Ozonioterapia no tratamento de ferida contaminada em canídeo (CANIS LUPUS FAMILIARIS)-Relato de caso. Revista Investigação, 17(4). https://doi.org/10.26843/investigacaov1742018p\%25p.

Silva, T. C., Shiosi, R. K., \& Raineri Neto, R. (2018). Ozonioterapia: um tratamento clínico em ascensão na medicina veterinária-revisão de literatura. Revista Cientifica de Medicina Veterinária, XV(31).

Sousa, F. B. (2009). Auto-hemoterapia como terapia auxiliar no tratamento de tumor venéreo transmissível. Universidade Ucb.

Srinivasan, K., \& Chitra, S. (2015). The application of ozone in dentistry: a systematic review of literature. Scholar Journal of Dental Sciences, 2(6), 373-377. https://doi.org/10.1016/j.jdent.2008.11.002.

Teixeira, L. R., Luna, S. P. L., Taffarel, M. O., Lima, A. F. M., Sousa, N. R., \& Joaquim, J. G. F. (2013). Comparison of intrarectal ozone, ozone administered in acupoints and meloxicam for postoperative analgesia in bitches undergoing ovariohysterectomy. The Veterinary Journal, 197(3), 794-799.

Tiwari, S., Avinash, A., Katiyar, S., Iyer, A. A., \& Jain, S. (2017). Dental applications of ozone therapy: A review of literature. The Saudi Journal for Dental Research, 8(1-2), 105-111. https://doi.org/10.1016/j.sjdr.2016.06.005.

Traldi, R. F. (2019). Uso da ozonioterapia como terapia complementar em cães diagnosticados com parvovirose. Universidade Estadual Paulista.

Wollheim, C., Gonçalves, E. S., Lopes, K. C., \& Bega, A. (2020). Efeito microbicida do ozônio gasoso em Pseudomonas aeruginosa, Staphylococcus aureus e Candida albicans. Revista Ibero-Americana de Podologia, 2(1), 121-125. https://doi.org/10.36271/iajp.v2i1.22.

Xiao, W., Tang, H., Wu, M., Liao, Y., Li, K., Li, L., \& Xu, X. (2017). Ozone oil promotes wound healing by increasing the migration of fibroblasts via PI3K/Akt/mTOR signaling pathway. Bioscience Reports, 37(6). https://doi.org/10.1042/BSR20170658.

Histórico do artigo:

Recebido: 27 de janeiro de 2021

Aprovado: 5 de março de 2021.
Licenciamento: Este artigo é publicado na modalidade Acesso Aberto sob a licença Creative Commons Atribuição 4.0 (CC-BY 4.0), a qual permite uso irrestrito, distribuição, reprodução em qualquer meio, desde que o autor e a fonte sejam devidamente creditados 